\title{
Neuron-Adaptive PID Based Speed Control of SCSG Wind Turbine System
}

\author{
Shan Zuo, ${ }^{1}$ Yongduan Song, ${ }^{1,2}$ Lei Wang, ${ }^{1,2}$ and Zheng Zhou ${ }^{3}$ \\ ${ }^{1}$ Institute of Intelligent System and Renewable Energy Technology, University of Electronic Science and Technology of China, \\ Chengdu 611731, China \\ ${ }^{2}$ Intelligent Systems and New Energy Technology Research Institute, Chongqing University, Chongqing 400044, China \\ ${ }^{3}$ Web Science Center, University of Electronic Science and Technology of China, Chengdu 611731, China
}

Correspondence should be addressed to Lei Wang; leiwang08@cqu.edu.cn

Received 11 March 2014; Accepted 14 April 2014; Published 19 May 2014

Academic Editor: Shen Yin

Copyright (C) 2014 Shan Zuo et al. This is an open access article distributed under the Creative Commons Attribution License, which permits unrestricted use, distribution, and reproduction in any medium, provided the original work is properly cited.

In searching for methods to increase the power capacity of wind power generation system, superconducting synchronous generator (SCSG) has appeared to be an attractive candidate to develop large-scale wind turbine due to its high energy density and unprecedented advantages in weight and size. In this paper, a high-temperature superconducting technology based large-scale wind turbine is considered and its physical structure and characteristics are analyzed. A simple yet effective single neuron-adaptive PID control scheme with Delta learning mechanism is proposed for the speed control of SCSG based wind power system, in which the RBF neural network (NN) is employed to estimate the uncertain but continuous functions. Compared with the conventional PID control method, the simulation results of the proposed approach show a better performance in tracking the wind speed and maintaining a stable tip-speed ratio, therefore, achieving the maximum wind energy utilization.

\section{Introduction}

With the fast development of wind power generation systems, the generating capacity of wind turbines is expected to reach up to $10 \mathrm{MW}$ [1]. Consequently, the wind turbine weight and size have to be increased simultaneously, with the bald diameter reaching up to 10 meters [2], as shown in Figure 1, which imposes technical difficulty in designing, transporting, and installing such large turbine blades. To address this challenge, novel concept of wind turbine generators with high energy density is urgently needed. High-temperature superconducting (HTS) technology is an expected solution. The research of wind turbines with SCSG has gained worldwide attention during the past decade [3-11].

Among various issues related to SCSG wind power generation systems, speed control represents one of the most crucial ones. Because of the inherent nonlinear and uncertain characteristics of the system, traditional PID control, although simple in structure and used widely in industry, is difficult to achieve reliable variable speed control performance in the blow-rated speed region.

To address this issue, several advanced control approaches have been studied, such as single neuron-adaptive PID control approach, BP neural network PID control approach, fuzzy RBF neural network PID control approach, genetic algorithm PID control approach, and adaptive fuzzy PID control approach. However, previous studies show that the response time of single neuron-adaptive PID is comparatively long, and most of the existing algorithms are computationally expensive, and some of them even lead to larger overshoot than traditional PID. The neural network control approach with self-learning and strong self-adaptive characteristics can effectively reduce the negative impact arising from the system parametric uncertainties and stochastic disturbances. Motivated by this fact, in this paper, a single neuronadaptive PID controller based on Delta learning regulation is introduced, in which the RBF neural network is employed to estimate the uncertain but continuous function. Analysis and 


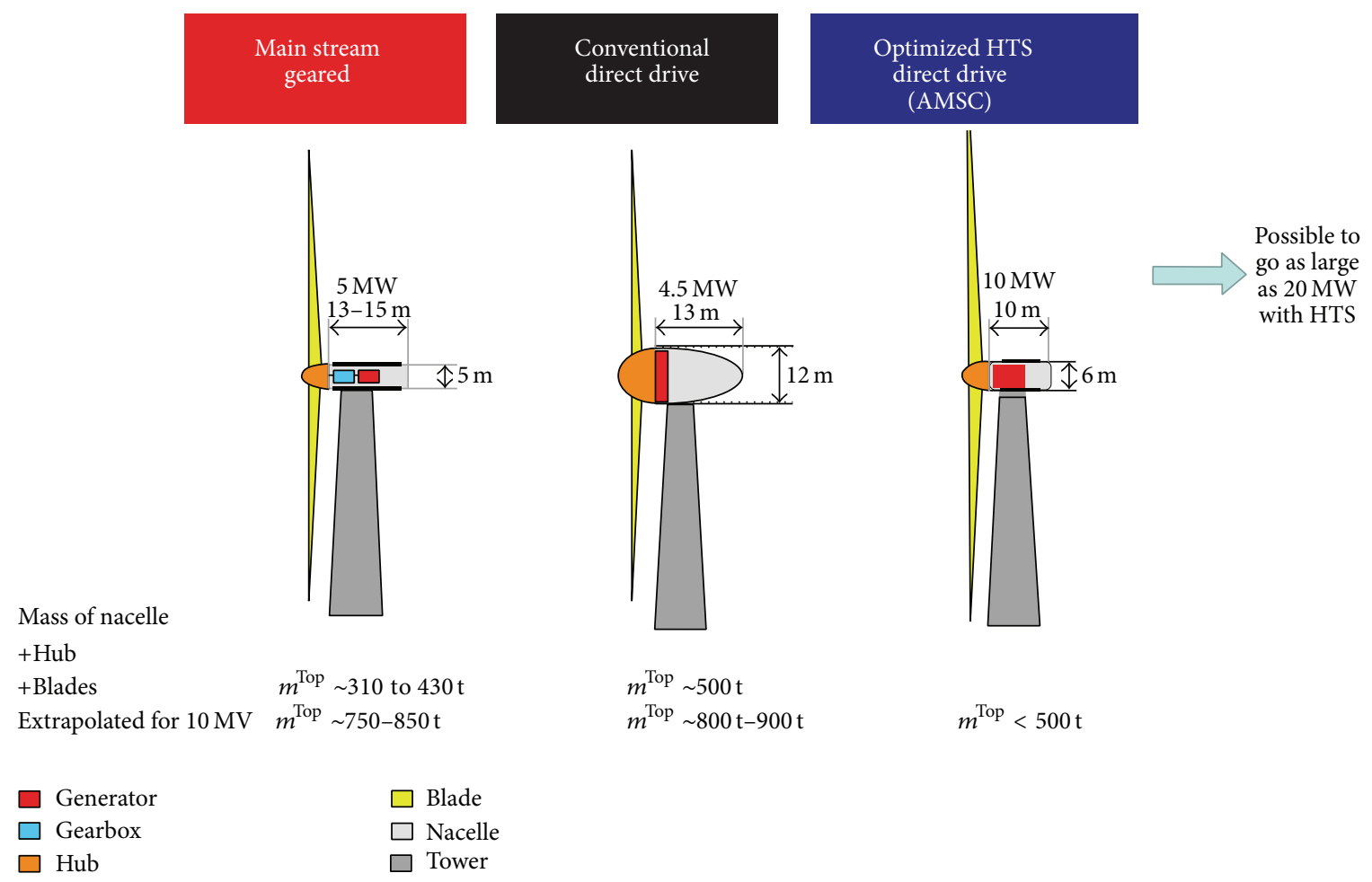

FIGURE 1: Comparison of nacelle sizes for technology options for large systems (image from American Superconductor).

simulation results show that the proposed control approach has better performance in terms of robustness, stability, and computational cost as compared with other modified PID methods, thus being mode suitable for the speed control of SCSG wind turbine systems.

\section{Dynamic System Modeling}

2.1. Configuration of the Superconducting Generator. The SCSG for wind turbine system has a multiple synchronous high-temperature superconducting (HTS) field winding for direct drive train and has been widely studied worldwide. Figure 2 shows the configuration of the 10 MW SCSG wind power generation system, including the wind turbine, the generator, and the convertor [12]. Physical properties and electrical properties of the designed SCSG are given in Tables 1 and 2 , respectively [1].

2.2. Modeling of the Superconducting Synchronous Generation System. It is well known that the expression for power produced by a wind turbine is simply given by

$$
P_{S}=\frac{1}{2} C_{p}(\lambda, \beta) \rho \pi R^{2} v^{3}
$$

where $\rho$ is air density, $R$ is the radius of rotor, and $v$ is wind speed passing the rotor. $C_{p}$ denotes power coefficient of wind turbine, which is a function of the tip-speed ratio $\lambda$ and the pitch angle $\beta$ [13].
TABle 1: Physical properties of the designed SCSG.

\begin{tabular}{lccc}
\hline Items & Value & Items & Value \\
\hline $\begin{array}{l}\text { Rated power } \\
\begin{array}{l}\text { Rated line to line } \\
\text { voltage }\end{array}\end{array}$ & $10 \mathrm{MW}$ & Number of poles & 24 \\
$\begin{array}{l}\text { Rated armature } \\
\text { current }\end{array}$ & $418 \mathrm{~A}$ & $\begin{array}{c}\text { Number of phases } \\
\text { Rated frequency }\end{array}$ & $2 \mathrm{~Hz}$ \\
$\begin{array}{l}\text { Rated rotating } \\
\text { speed }\end{array}$ & $100 \mathrm{~A}$ & $\begin{array}{c}\text { Length of HTS } \\
\text { wire } \\
\text { Operating } \\
\text { temperature }\end{array}$ & $919 \mathrm{~km}$ \\
\hline
\end{tabular}

TABLE 2: Electrical properties of the designed SCSG.

\begin{tabular}{lc}
\hline Items & Value \\
\hline Turns of stator coil & 28 \\
Number of slots & 144 \\
Number of slots per pole per phase & 2 \\
Current density of stator wire & $5 \mathrm{~A} / \mathrm{mm}^{2}$ \\
Space factor of stator wire & 0.4 \\
Turns of field coil & 1500 \\
\hline
\end{tabular}

Note that the tip-speed ratio is defined by

$$
\lambda=\frac{v_{\text {Tip }}}{v}=\frac{R \omega}{v},
$$

where $v_{\text {Tip }}$ is the tip-speed and $\omega$ is the rotor speed. 


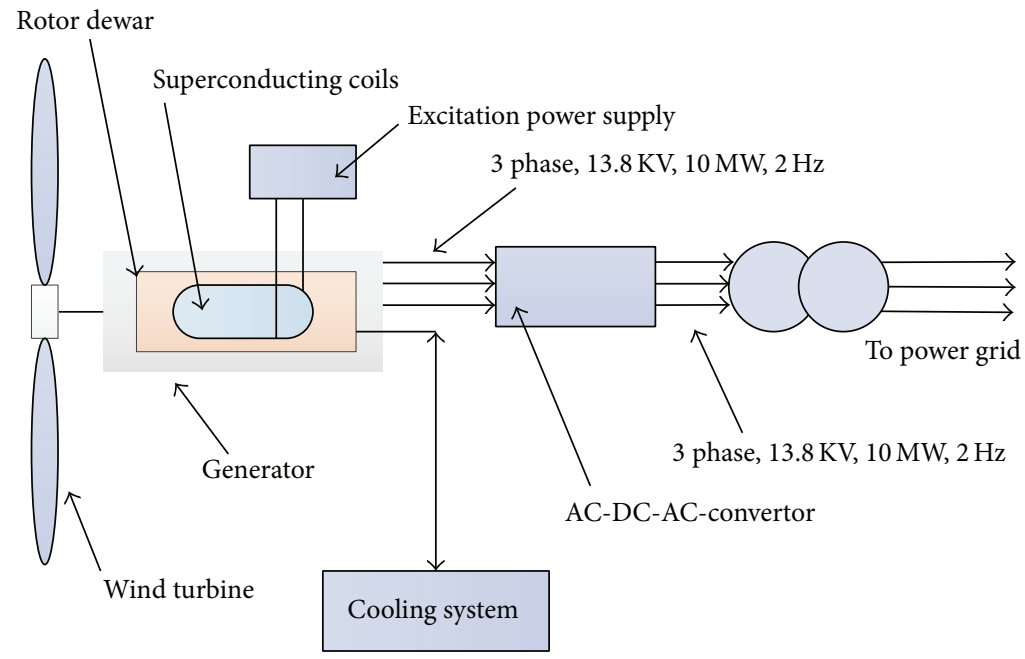

FIgUre 2: Configuration of the 10 MW SCSG system.

In the lower-rated wind speed region, the maximum power point tracking (MPPT) control approach is adopted. The maximum power of the wind turbine is expressed as [14]

$$
P_{\max }=\frac{1}{2} \frac{\rho \pi R^{5} C_{p_{-} \max }}{\lambda_{\mathrm{opt}}^{3}} \omega^{3} .
$$

Table 3 shows the specifications of the modeled $10 \mathrm{MW}$ SCSG wind turbine [2].

For the purpose of the studies presented in this paper, a standard ( $d q$-frame) synchronous machine simulation model has been used with parameters resembling the main characteristics of a notional $10 \mathrm{MW}$ HTS generator along with the associated controls. This notional simulation model of the HTS generator is loosely based on the parameters of an actual prototype in order to safeguard the proprietary information of the manufacturer. The mechanical input for the notional HTS generator originates from the wind turbine model.

In the rotor $d q$-rotating coordinate system, the generator flux model is shown in (4)

$$
\begin{gathered}
\Psi_{s d}=L_{s \sigma} i_{d}+\left(L_{m d} i_{d}+M_{s f} i_{f}+M_{s D} i_{D}\right), \\
\Psi_{s q}=L_{s \sigma} i_{q}+\left(L_{m q} i_{q}+M_{s Q} i_{Q}\right), \\
\Psi_{f}=L_{f \sigma} i_{f}+\left(\frac{3}{2} M_{s f} i_{d}+L_{m f} i_{f}+M_{f D} i_{D}\right), \\
\Psi_{D}=L_{D \sigma} i_{D}+\left(\frac{3}{2} M_{s D} i_{d}+L_{m D} i_{D}+M_{f D} i_{f}\right), \\
\Psi_{\mathrm{Q}}=L_{\mathrm{Q} \sigma} i_{\mathrm{Q}}+\left(\frac{3}{2} M_{s Q} i_{q}+L_{m Q} i_{\mathrm{Q}}\right) .
\end{gathered}
$$

$\Psi_{s d}, \Psi_{s q}$ are the orthogonal axes flux of the stator; $\Psi_{f}$ is rotor excitation flux; $\Psi_{D}, \Psi_{\mathrm{Q}}$ are orthogonal axes flux of the damping winding; $i_{d}, i_{q}$ are the orthogonal axes currents of the stator; $i_{f}$ is rotor excitation current; $i_{D}, i_{Q}$ are orthogonal
TABLE 3: Model parameters of the designed SCSG.

\begin{tabular}{lcc}
\hline Items & Symbol & Value \\
\hline Rated power & $P_{N}$ & $10 \mathrm{MW}$ \\
Rated rotor speed & $n_{r}$ & $10 \mathrm{RPM}$ \\
Rotor radius & $R$ & $85 \mathrm{~m}$ \\
Maximum power coefficient & $C_{p-\max }$ & 0.48 \\
Optimum tip-speed ratio & $\lambda_{\text {opt }}$ & 7 \\
Air density & $\rho$ & $1.225 \mathrm{~kg} / \mathrm{m}^{3}$ \\
\hline
\end{tabular}

axes currents of damper winding. $L_{s \sigma}, L_{f \sigma}, L_{D \sigma}$, and $L_{\mathrm{Q} \sigma}$ are leakage inductances, respectively, for stator winding, field winding, and orthogonal axis damper winding. $L_{m d}, L_{m q}$ are armature reaction inductances for orthogonal axis. $M_{s f}$, $M_{s D}$, and $M_{s \mathrm{Q}}$ are mutual inductances between the stator winding, rotor field winding, and the orthogonal axis damper winding. $L_{m f}, L_{m D}$, and $L_{m \mathrm{Q}}$ are inductances corresponding to the main magnetic circuit in the self-inductance of the field winding and the orthogonal axis damper winding.

Assume

$$
\begin{aligned}
& L_{d}=L_{s \sigma}+L_{m d}, \\
& L_{q}=L_{s \sigma}+L_{m q}, \\
& L_{f}=L_{f \sigma}+L_{m f}, \\
& L_{D}=L_{D \sigma}+L_{m D}, \\
& L_{\mathrm{Q}}=L_{\mathrm{Q} \sigma}+L_{m Q},
\end{aligned}
$$

where $L_{d}, L_{q}$ are the orthogonal axis inductances of the motor; $L_{f}$ is the self-inductance of the rotor field winding; $L_{D}, L_{\mathrm{Q}}$ are the self-inductances of orthogonal axis damper winding.

According to formula (5), the flux mathematical model in formula (4) could be further simplified. 


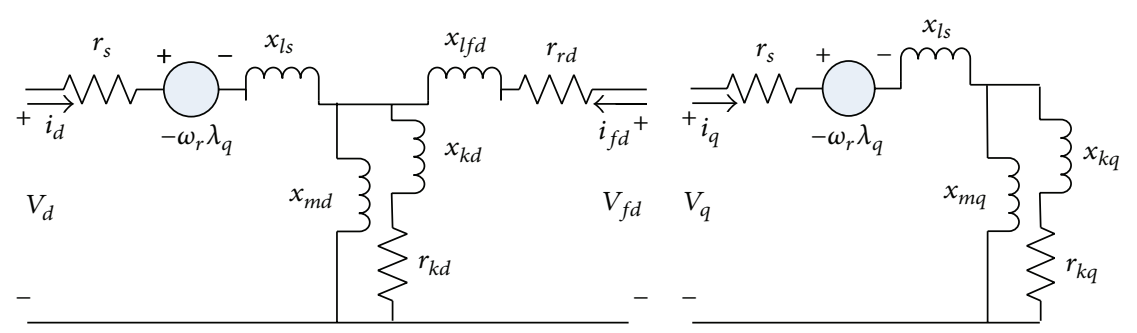

FIGURE 3: Equivalent circuits of the modeled SCSG for $d q$-axes.

The voltage balance equations of stator and rotor windings are shown in (6)

$$
\begin{gathered}
u_{d}=r_{s} i_{d}+\frac{d \Psi_{s d}}{d t}-\Psi_{s q} \frac{d \theta_{r}}{d t}, \\
u_{q}=r_{s} i_{q}+\frac{d \Psi_{s q}}{d t}+\Psi_{s d} \frac{d \theta_{r}}{d t}, \\
u_{f}=r_{f} i_{f}+\frac{d \Psi_{f}}{d t}, \\
r_{D} i_{D}+\frac{d \Psi_{D}}{d t}=0, \\
r_{Q} i_{Q}+\frac{d \Psi_{Q}}{d t}=0,
\end{gathered}
$$

where $r_{s}, r_{f}, r_{D}$, and $r_{Q}$ are the resistances of the stator winding, rotor field winding, and orthogonal axis damping winding, respectively. mula

The electromagnetic torque expression is shown in for-

$$
T_{e}=\frac{3}{2} p\left(\Psi_{s d} i_{q}-\Psi_{s q} i_{d}\right)
$$

where $p$ is the number of pole pairs of the generator.

Figure 3 shows the $d-q$ equivalent circuit model of the designed SCSG based on Park's transformations.

In order to allow operation at different speeds, the designed SCSG model is linked to the power grid via a fullscale frequency inverter. The frequency converter consists of a generator side converter, a grid side rectifier, and a DC-link. The generator side converter executes the MPPT control through the control of the $q$-axis current. The grid side rectifier performs reactive power control and constant DC voltage control through control of the $d$-axis and $q$ axis currents. Figure 4 depicts the structure of the full-scale frequency inverter. Figure 5 shows controller implementation of the generator side converter and the grid side rectifier.

The simulation model of the generator drive used in this paper utilizes ideal voltage sources representing the fundamental frequency component of a PWM-type variable speed drive. It includes a current control and a speed control. The control target of the speed control is to keep the expected steady state and dynamic characteristic of the rotor speed $\omega$. The paper utilizes a single neuron-adaptive PID control approach based on RBF to achieve this control goal [15].

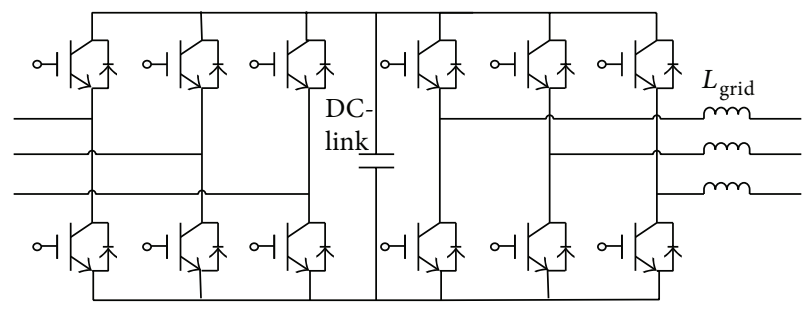

FIgURE 4: Structure of the full-scale frequency inverter.

Figure 6 represents the overall structure diagram of the SCSG wind turbine generation system mounted with associated controllers.

\section{Design of Controller}

3.1. Incremental PID Control Approach. Equations of the incremental PID control approach are defined as follows:

$$
\begin{gathered}
u(k)=u(k-1)+\Delta u(k), \\
\Delta u(k)=k_{p}[e(k)-e(k-1)]+k_{i} e(k) \\
+k_{d}[e(k)-2 e(k-1)+e(k-2)] .
\end{gathered}
$$

Equation (8) shows that the three control parameters $\left(k_{p}\right.$, $k_{i}$, and $k_{d}$ ) cannot be real-time adjusted, which result in a decrease in the response speed of system.

3.2. Single Neuron-Adaptive PID Controller Algorithm. Combining single neuron to the incremental PID can address the challenge of real-time adjustment of control parameters. The single neuron-adaptive PID control structure is illustrated in Figure 7.

Improved single neuron-adaptive PID control algorithm based on Delta learning rule implements the adjustment of the three weights in incremental PID controller, therefore, achieving adaptive control.

Delta learning rule based on the steepest descent method completes the aim to adjust the three weights by minimizing the introduced performance indicator.

Assume the weight value at time $k$ in the incremental PID controller is to be expressed as $w_{j}(k), j=p, i, d$, and the weight value adjusting formula of next moment is expressed as

$$
w_{j}(k)=w_{j}(k-1)+\Delta w_{j}(k)
$$



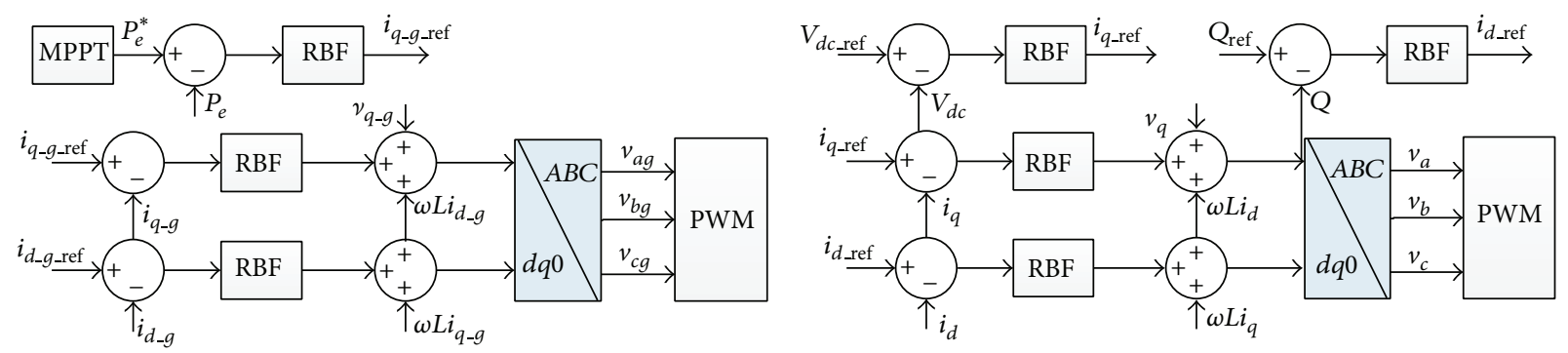

FIGURE 5: Controller implementation of the full-scale frequency inverter.

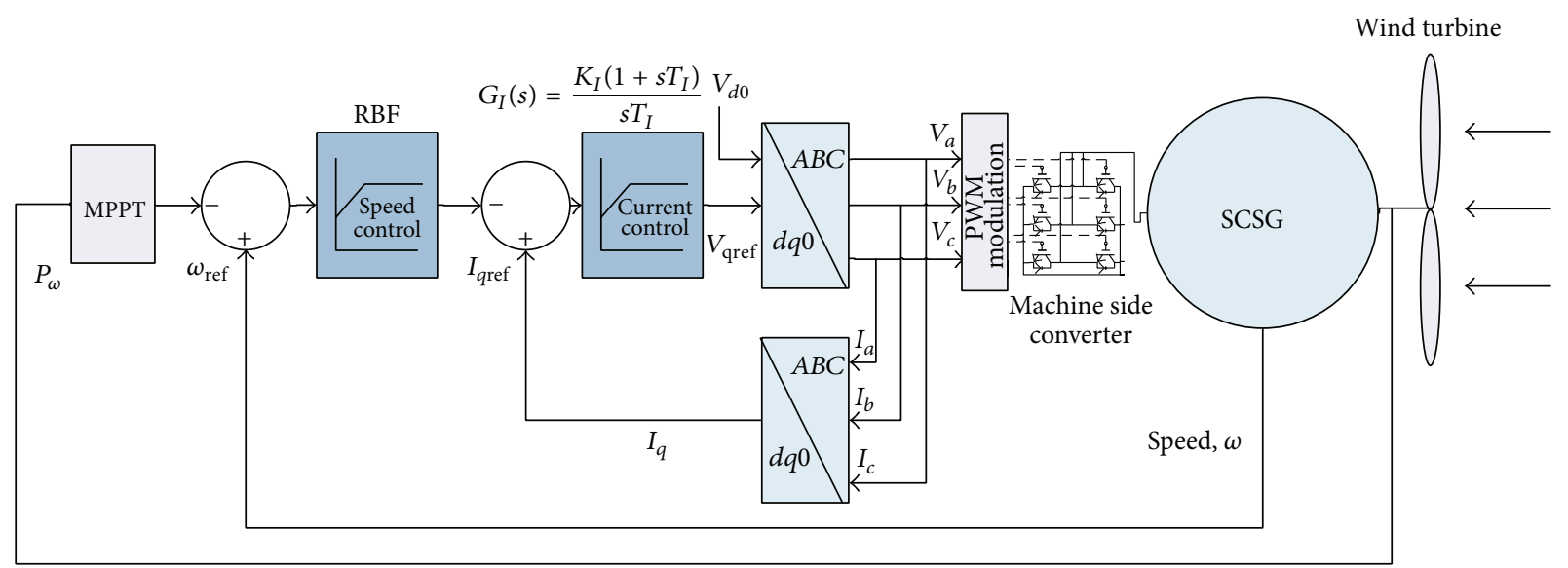

FIGURE 6: Structure diagram of overall wind turbine generation system.

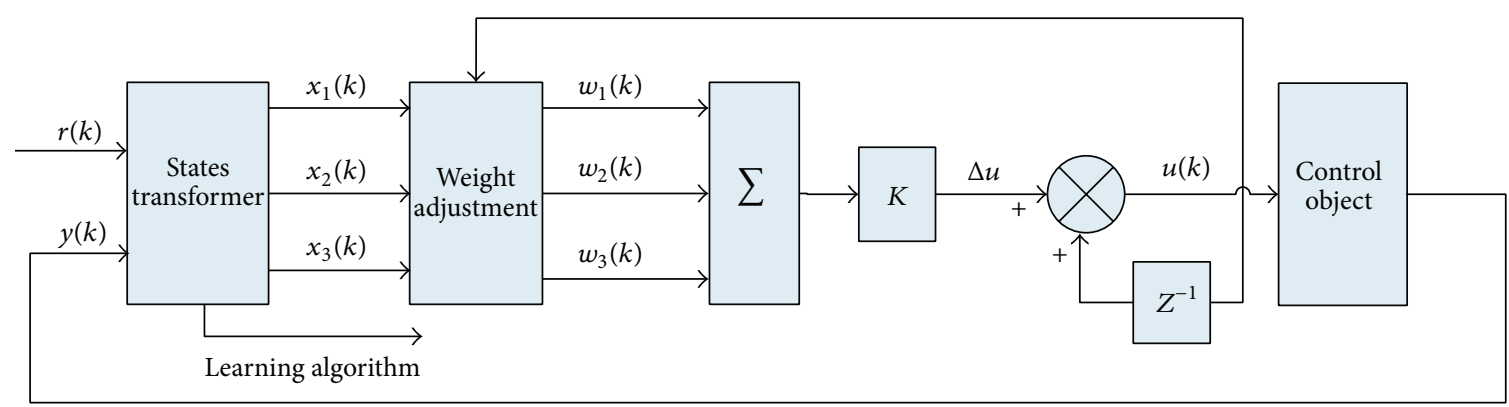

FIGURE 7: The block diagram of the single neuron-adaptive PID controller.

where $\Delta w_{j}(k)$ is the weight increment. Introduce the output error square function as the performance indicator, namely,

$$
F\left[w_{j}(k)\right]=\frac{1}{2}[r(k)-y(k)]^{2}=\frac{1}{2}[z(k)]^{2},
$$

where $r(k)$ and $y(k)$ are input and output of the reference.

Each time the amendments are to meet

$$
F\left[w_{j}(k)\right]<F\left[w_{j}(k-1)\right] .
$$

First-order Taylor expansion of $F\left[w_{j}(k)\right]$ is expressed as

$$
\begin{aligned}
F\left[w_{j}(k)\right] & =F\left[w_{j}(k-1)+\Delta w_{j}(k)\right] \\
& \approx F\left[w_{j}(k-1)\right]+g^{T}(k) \Delta w_{j}(k),
\end{aligned}
$$

where $g(k)=\nabla F\left[w_{j}(k)\right]$.
In the above formula, $g(k)$ is the gradient vector of $F[w]$ when $w=w_{j}(k)$. Assume $\Delta w_{j}(k)=-\eta_{j} g(k)$, where $\eta_{j}$ is the learning rate, which is a small positive value. Formula (11) is bound to meet.

The value of $\Delta w_{j}(k)$ is expressed as

$$
\begin{aligned}
\Delta w_{j}(k) & =w_{j}(k)-w_{j}(k-1) \\
& =-\eta_{j} \frac{\partial F(w)}{\partial w_{j}(k)}=\eta_{j} z(k) \frac{\partial y(k)}{\partial \Delta u(k)} \frac{\partial \Delta u(k)}{\partial w_{j}(k)},
\end{aligned}
$$

where $(\partial y(k)) /(\partial \Delta u(k))$ is unknown and in the case when calculation accuracy is not strictly required, replace it with 
the sign function $\operatorname{sgn}((\partial y(k)) /(\partial \Delta u(k)))$. Standardizing the above algorithm, we can get

$$
\begin{gathered}
w_{p}(k)=w_{p}(k-1)+\eta_{p} z(k) \operatorname{sgn}\left(\frac{\partial y(k)}{\partial \Delta u(k)}\right) x_{1}(k), \\
w_{i}(k)=w_{i}(k-1)+\eta_{i} z(k) \operatorname{sgn}\left(\frac{\partial y(k)}{\partial \Delta u(k)}\right) x_{2}(k), \\
w_{d}(k)=w_{d}(k-1)+\eta_{d} z(k) \operatorname{sgn}\left(\frac{\partial y(k)}{\partial \Delta u(k)}\right) x_{3}(k),
\end{gathered}
$$

where

$$
\operatorname{sgn}(x)= \begin{cases}+1, & x \gg 0 \\ -1, & x<0\end{cases}
$$

Introducing a gain factor $K$, we can get

$$
\begin{aligned}
u(k)= & u(k-1) \\
& +K\left[w_{p}(k) x_{1}(k)+w_{i}(k) x_{2}(k)+w_{d}(k) x_{3}(k)\right] .
\end{aligned}
$$

3.3. Improved Single Neuron PID Using RBF Neural Network. Neural network (NN) is a powerful approach to linearize and approximate any continuous nonlinear control system, in which radial basis function (RBF) network is a three-layer forward network. RBF network is composed of an input layer, a single hidden layer with nonlinear nodes, and an output layer with a linear node. The topological structure of a typical RBF network is depicted in Figure 8.

The control block diagram of a typical RBF neural network is illustrated in Figure 9.

In RBF network, $X=\left[x_{1}, x_{2}, \ldots, x_{n}\right]^{T}$ is the input vector and $h_{g}$ is activation function, which is given by

$$
h_{g}=\exp \left(-\frac{\left\|X-C_{g}\right\|^{2}}{2 b_{g}^{2}}\right), \quad g=1,2, \ldots, m
$$

where $C_{g}=\left[C_{1 g}, C_{2 g}, \ldots, C_{i g}, \ldots, C_{n g}\right]^{T}$ is the central vector of $g$ th hidden neuron. $B=\left[b_{1}, b_{2}, \ldots, b_{g}, \ldots, b_{m}\right]^{T}$ is the basis-width vector, $b_{g}>0$ is the base width constant of $g$ th mode, and the weight vector of the network is $w=$ $\left[w_{1}, w_{2}, \ldots, w_{g}, \ldots, w_{m}\right]^{T}$.

The output of the $m$ th neuron in the output layer at time $k$ is defined as

$$
y_{m}(k)=w H=w_{1} h_{1}+w_{2} h_{2}+\cdots+w_{m} h_{m} .
$$

The performance of network can be evaluated by

$$
E=\frac{1}{2}\left[y(k)-y_{m}(k)\right]^{2} .
$$

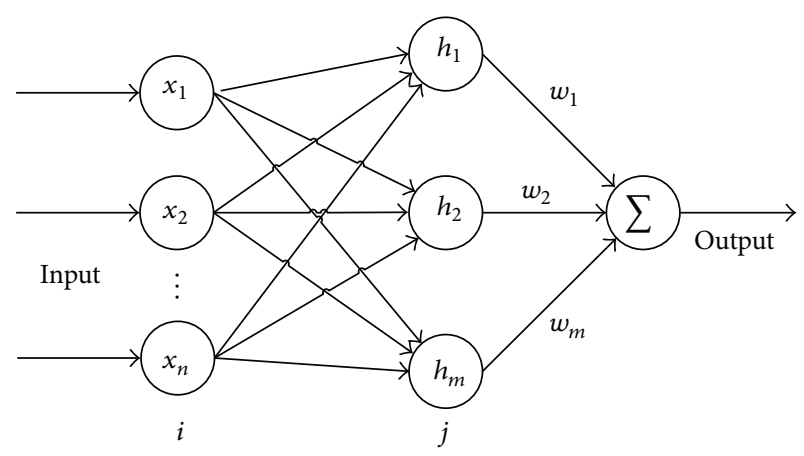

FIgURE 8: Topological graph of RBF neural network.

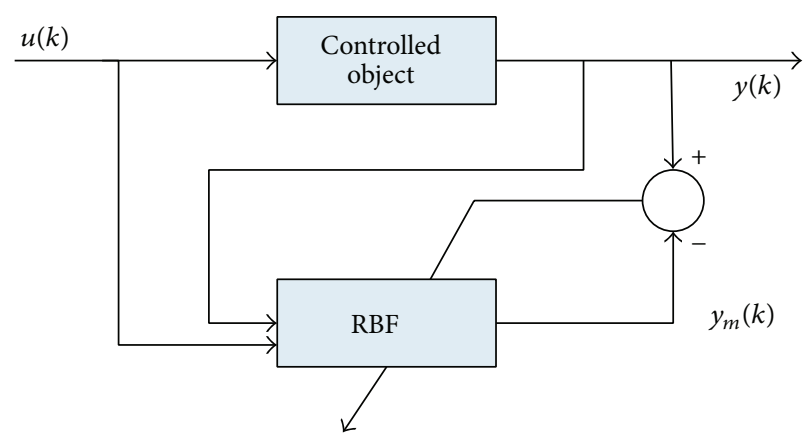

FIGURE 9: Control block diagram of RBF neural network.

Using the gradient descent method, we can get the iterative algorithm of output weight, central vector of mode, and base width constant expressed as follows:

$$
\begin{gathered}
w_{g}(k)=w_{g}(k-1)+\beta\left(y(k)-y_{m}(k)\right) h_{g} \\
+\alpha\left[w_{g}(k-1)-w_{g}(k-2)\right], \\
\Delta b_{g}=\left[y(k)-y_{m}(k)\right] w_{g} h_{g} \frac{\left\|X-C_{g}\right\|^{2}}{b_{g}^{3}}, \\
b_{g}(k)=b_{g}(k-1)+\beta \Delta b_{g}+\alpha\left[b_{g}(k-1)-b_{g}(k-2)\right], \\
\Delta c_{i g}=\left[y(k)-y_{m}(k)\right] w_{g} \frac{x_{g}-c_{i g}}{b_{g}^{2}}, \\
c_{i g}(k)=c_{i g}(k-1)+\beta \Delta c_{i g}+\alpha\left[c_{i g}(k-1)-c_{i g}(k-2)\right],
\end{gathered}
$$

where $\alpha$ is the momentum factor and $\beta$ is the learning rate.

At time $k,(\partial y(k)) /(\partial \Delta u(k)) \approx\left(\partial y_{m}(k)\right) /(\partial \Delta u(k))$, since $X$ is a one-dimensional vector, containing $\Delta u$; therefore $\partial X / \partial \Delta u=1$; then, we can write the Jacobian matrix of the control system as follows:

$$
\frac{\partial y_{m}(k)}{\partial \Delta u(k)}=\frac{\partial \sum_{g=1}^{m} w_{g} h_{g}}{\partial \Delta u(k)}=\frac{\sum_{g=1}^{m} w_{g} \partial \exp \left(-\left\|X-C_{g}\right\|^{2} / 2 b_{g}^{2}\right)}{\partial \Delta u(k)}
$$




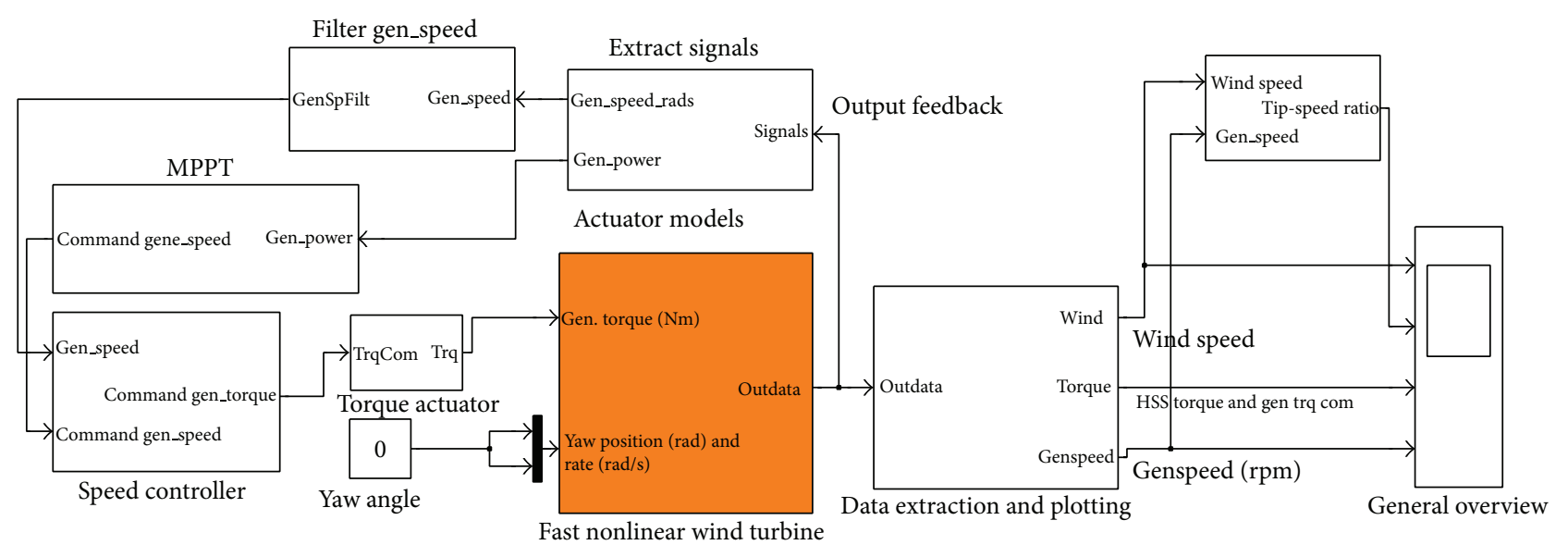

FIGURE 10: Simulation module of the SCSG wind generation system.

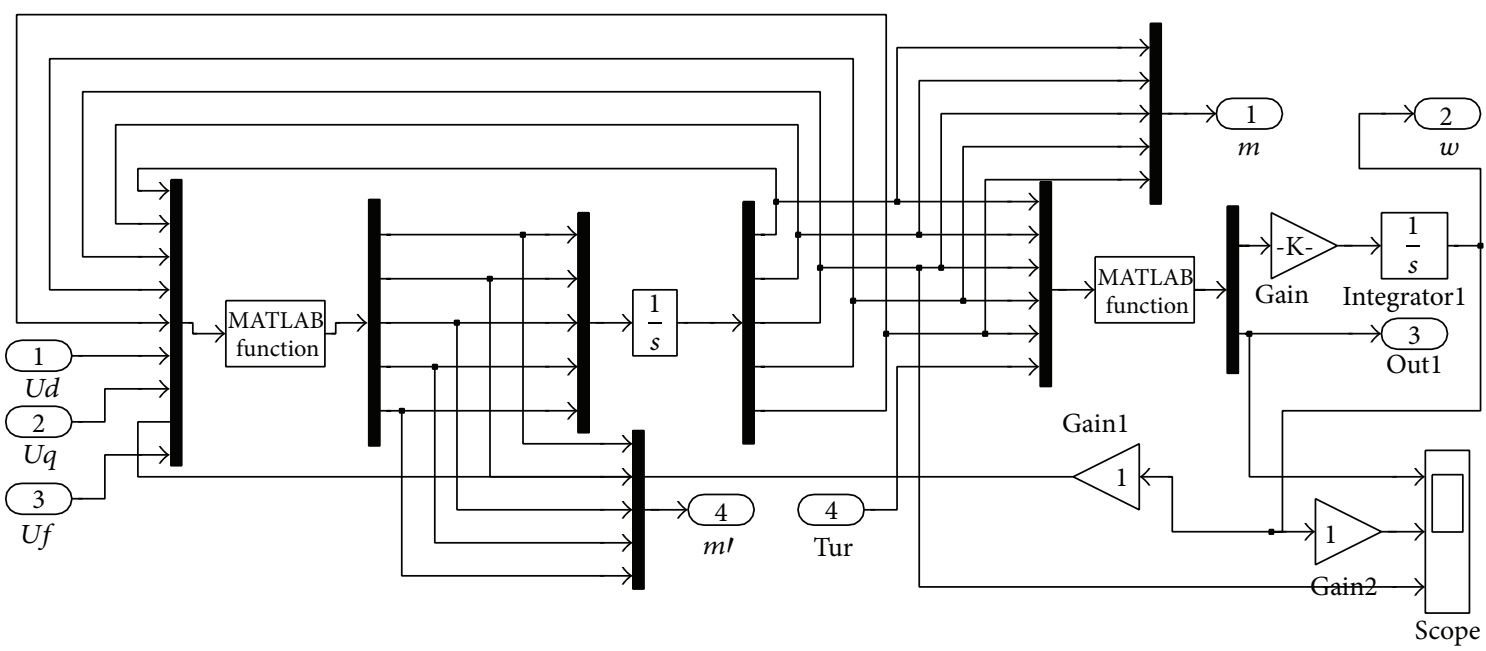

FIGURE 11: Simulation module of SCSG.

$$
\begin{aligned}
& =\frac{\sum_{g=1}^{m} w_{g} h_{g}\left(\left(C_{g}-X\right) / b_{g}^{2}\right) \partial X}{\partial \Delta u(k)} \\
& =\sum_{g=1}^{m} w_{g} h_{g} \frac{C_{g}-X}{b_{g}^{2}} .
\end{aligned}
$$

According to the universal approximation ability of the RBF neural network [16-28], we can conclude that

$$
\left\|y_{m}(k)-y(k)\right\|<\varepsilon,
$$

where $\varepsilon$ is a bounded positive constant.

\section{Simulations and Analysis}

The proposed neuron-adaptive PID speed control system of SCSG based on RBF neural network identification is depicted in Figure 6. The entire control module of the SCSG wind generation system is presented in Figure 10 and the simulation module of SCSG is depicted in Figure 11. Parameters of SCSG used in the simulation are listed in Tables 1,2, and 3. The reference model used in the simulation is taken as a constant speed. The simulation is tested with the MATLAB/Simulink and FAST (FAST is a fully coupled aero-hydro-servo-elastic code, freely available and developed at the National Renewable Energy Laboratory and used to simulate the loads and performance of modern wind turbines).

To verify the dynamic and static performances of the neuron-adaptive PID controller based on RBF NN proposed in this paper, simulation tests are designed in two cases: (1) no-load operation with a given speed of $10 \mathrm{r} / \mathrm{min}$; (2) system starts with no-load, after being in a steady state, given a sudden load $T_{l}=10 \mathrm{MN} \cdot \mathrm{m}$ at $t=2 \mathrm{~s}$. Simultaneously compared with the conventional PID controller, available system speed control response curves are demonstrated 


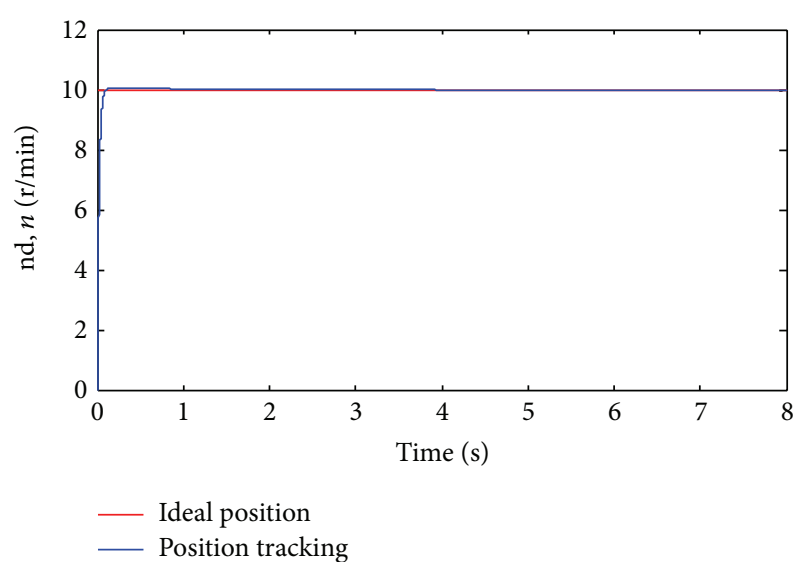

FIGURE 12: SCSG speed response curve to no-load operation with traditional PID controller.

from Figure 12 to Figure 16. Furthermore, after verifying the validity of the proposed control approach, the paper applies the proposed controller in the speed control of SCSG wind generation system in the below-rated wind speed region to better track wind speed and maintain a stable tip-speed ratio, therefore, achieving the maximum utilization of wind energy.

Figures 12 and 13 show that compared with the conventional PID controller, the speed response with the proposed controller is more rapid and smooth, with a smaller overshoot and no static error, solving the contradiction between response time and overshoot of the conventional PID control.

Figures 14 and 15 depict that compared with the conventional PID controller, system with the proposed controller is more robust. When the parameter perturbation occurs, the entire system is stable, with better transient characteristics and nonsteady state static error, and has a strong ability to inhibit the impact of load disturbance to generator speed.

Figure 16 shows the adaptive tuning curve of PID parameters $\left(k_{p}, k_{i}, k_{d}\right)$.

Figures 17 and 18 show the compared simulating results of two algorithms in speed control of SCSG tracking wind speed in wind power generation system. Obviously, the proposed control approach makes the SCSG speed better track the wind speed and achieve a more stable tip-speed ratio when the wind speed is below the rated wind speed $12 \mathrm{~m} / \mathrm{s}$, such that the SCSG wind power generation system makes better use of wind energy.

\section{Conclusion}

In this paper, the $10 \mathrm{MW}$ class superconducting wind turbine generator has been studied, and a single neuron-adaptive PID controller based on Delta learning regulation is proposed, using the RBF neural network to estimate the uncertain continuous function. Analysis and simulation results show that the proposed control approach in SCSG system has a strong robustness and good dynamic performance by keeping a stable output in the presence of disturbances. Furthermore,

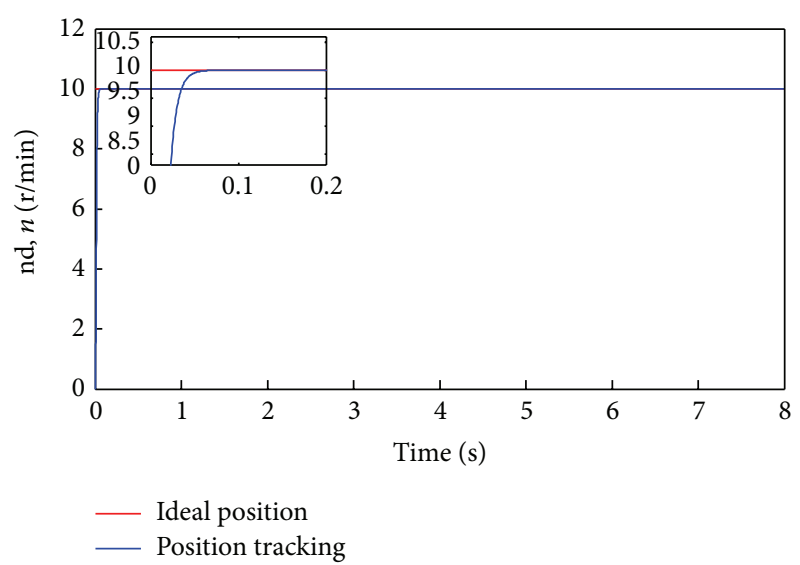

FIGURE 13: SCSG speed response curve to no-load operation with neuron-adaptive PID controller with RBF NN.

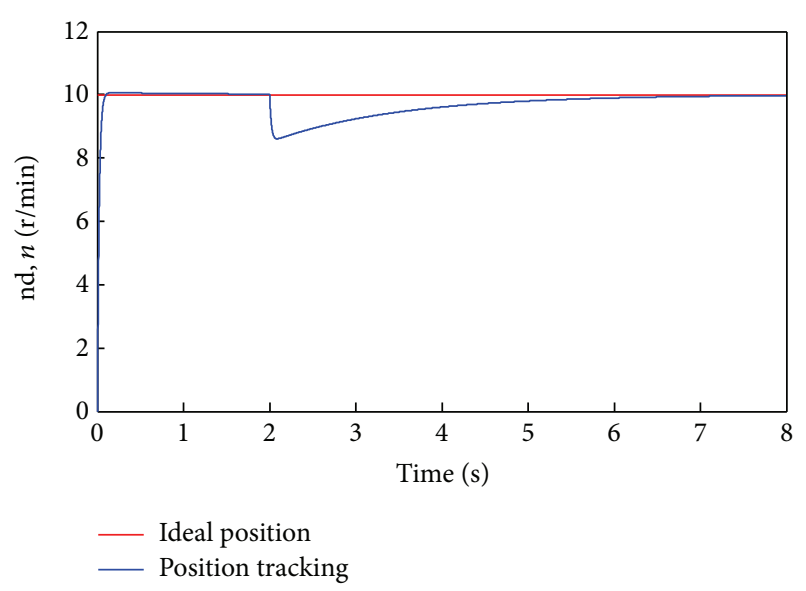

FIGURE 14: SCSG speed response curve to a sudden load with traditional PID controller.

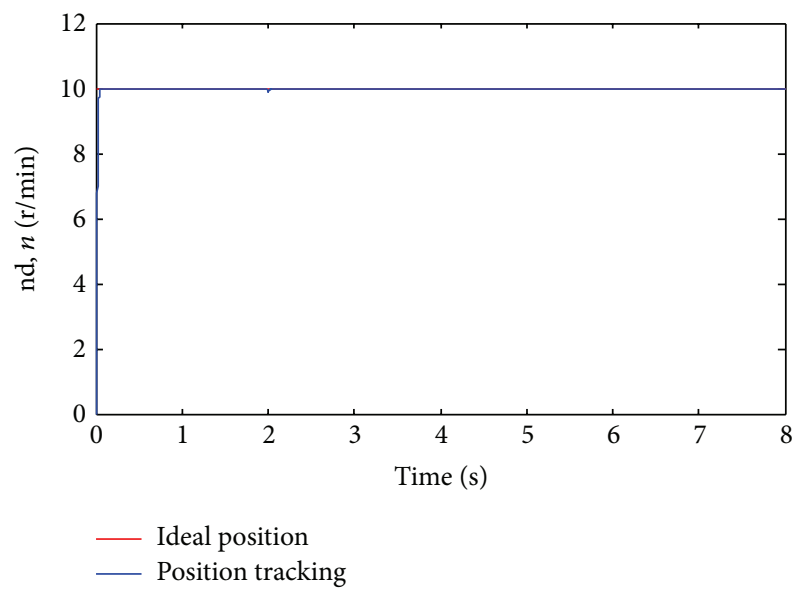

FIGURE 15: SCSG speed response curve to a sudden load with neuron-adaptive PID controller with RBF NN. 

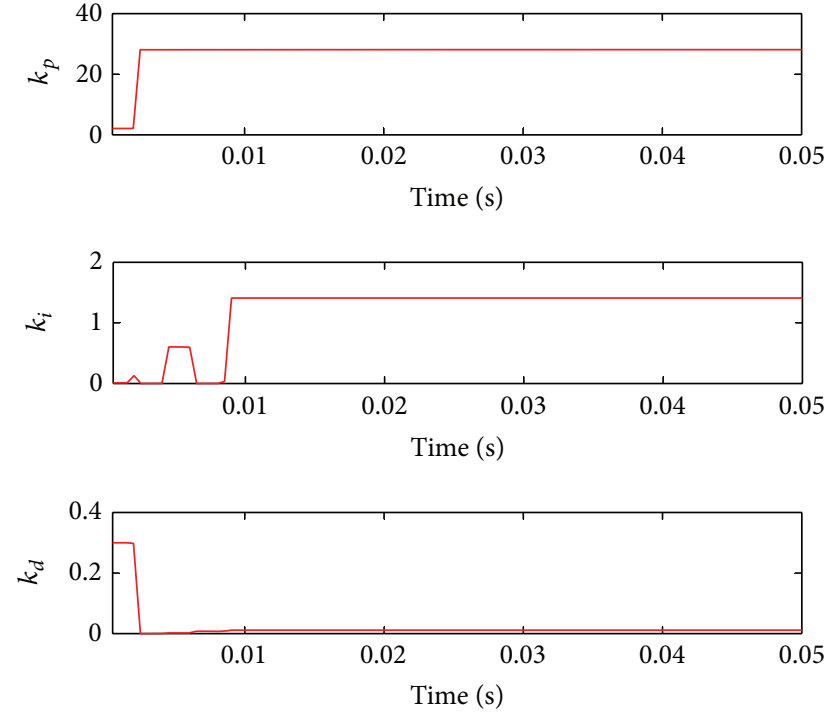

FIGURE 16: PID parameters adaptive tuning curve.

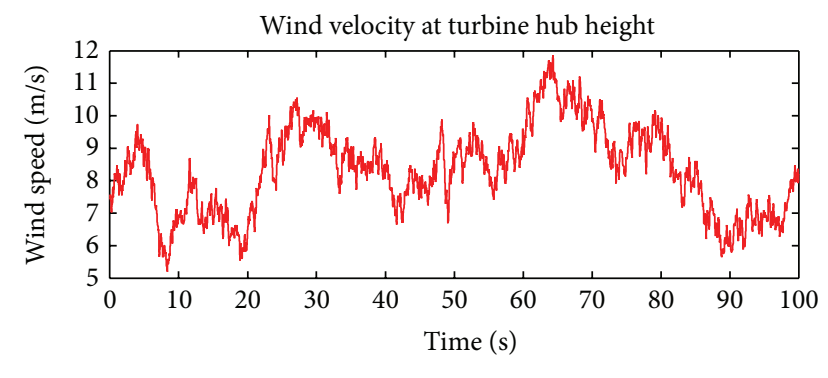

— Wind speed

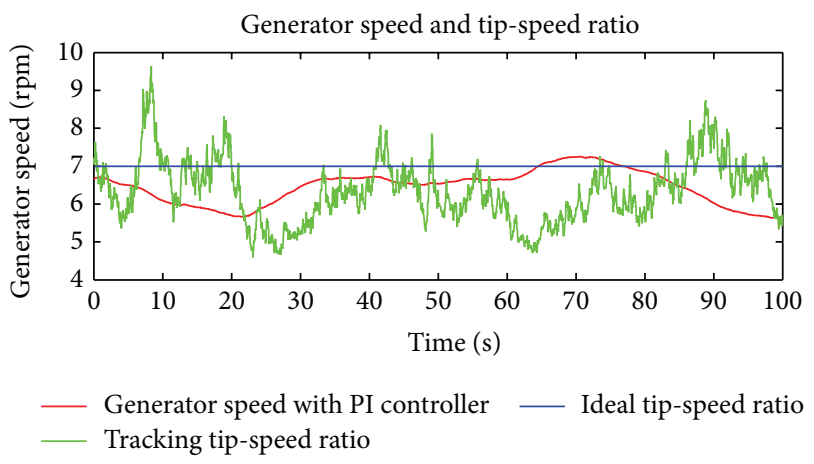

FIGURE 17: Simulation results of the speed control for SCSG wind turbine with conventional PID controller.

comparative study between the proposed controller and the conventional PID controller in the speed control of SCSG wind turbine system has also been conducted. Overall, the proposed control approach is able to achieve smooth and satisfactory rotor speed tracking, achieving the maximum wind energy utilization, in the below-rated wind speed region, and outperforms the traditional PID.

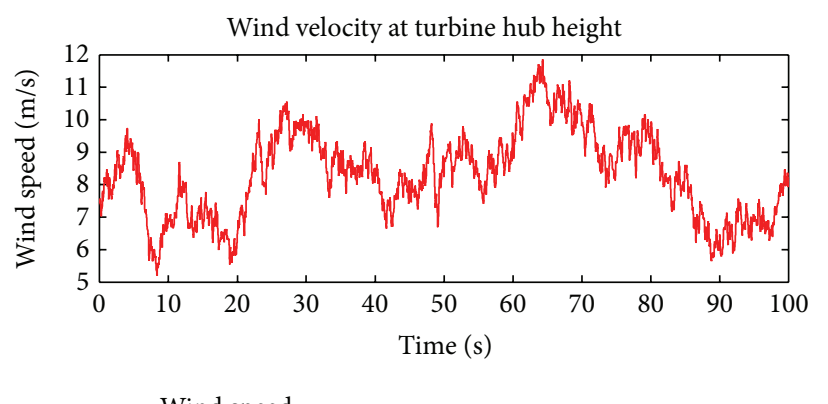

— Wind speed

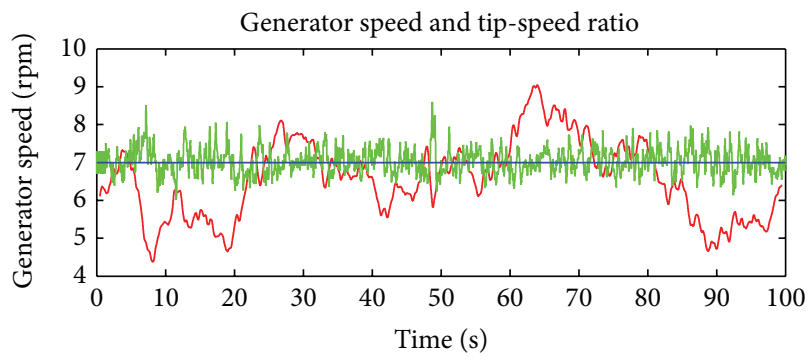

_ Generator speed with RBF controller __ Ideal tip-speed ratio — Tracking tip-speed ratio

FIGURE 18: Simulation results of the speed control for SCSG wind turbine with neuron-adaptive PID controller with RBF NN.

\section{Conflict of Interests}

The authors declare that there is no conflict of interests regarding the publication of this paper.

\section{Acknowledgments}

This work was supported by the Major State Basic Research Development Program 973 (no. 2012CB215202) and the National Natural Science Foundation of China (no. 51205046).

\section{References}

[1] G.-H. Kim, N. Kim, K.-M. Kim et al., "EMTDC based simulation of $10 \mathrm{MW}$ class grid-connected superconducting wind turbine generator," IEEE Transactions on Applied Superconductivity, vol. 22, no. 3, Article ID 5202105, 2012.

[2] H. Li, Z. Chen, and H. Polinder, "Optimization of multibrid permanent-magnet wind generator systems," IEEE Transactions on Energy Conversion, vol. 24, no. 1, pp. 82-92, 2009.

[3] C. Lewis and J. Muller, "A direct drive wind turbine HTS generator," in Proceedings of the IEEE Power Engineering Society General Meeting (PES '07), pp. 1-8, Tampa, Fla, USA, June 2007.

[4] A. B. Abrahamsen, N. Mijatovic, E. Seiler et al., "Design study of $10 \mathrm{~kW}$ superconducting generator for wind turbine applications," IEEE Transactions on Applied Superconductivity, vol. 19, no. 3, pp. 1678-1682, 2009.

[5] A. B. Abrahamsen, N. Mijatovic, E. Seiler et al., "Superconducting wind turbine generators," Superconductor Science and Technology, vol. 23, no. 3, Article ID 034019, 2010. 
[6] G. Snitchler, B. Gamble, C. King, and P. Winn, "10 MW class superconductor wind turbine generators," IEEE Transactions on Applied Superconductivity, vol. 21, no. 3, pp. 1089-1092, 2011.

[7] S. Fukui, J. Ogawa, T. Sato, O. Tsukamoto, N. Kashima, and S. Nagaya, "Study of $10 \mathrm{MW}$-class wind turbine synchronous generators with HTS field windings," IEEE Transactions on Applied Superconductivity, vol. 21, no. 3, pp. 1151-1154, 2011.

[8] S. Yin, H. Luo, and S. Ding, "Real-time implementation of faulttolerant control systems with performance optimization," IEEE Transactions on Industrial Electronics, vol. 64, no. 5, pp. 24022411, 2014.

[9] S. Yin, G. Wang, and H. R. Karimi, "Data-driven design of robust fault detection system for wind turbines," Mechatronics, 2013.

[10] S. Yin, S. X. Ding, A. H. A. Sari, and H. Hao, "Data-driven monitoring for stochastic systems and its application on batch process," International Journal of Systems Science, vol. 44, no. 7, pp. 1366-1376, 2013.

[11] S. Yin, S. X. Ding, A. Haghani, H. Hao, and P. Zhang, "A comparison study of basic datadriven fault diagnosis and process monitoring methods on the benchmark Tennessee Eastman process," Journal of Process Control, vol. 22, no. 9, pp. 1567-1581, 2012.

[12] X. Li, Y. Zhou, L. Han et al., "Design of a high temperature superconducting generator for wind power applications," IEEE Transactions on Applied Superconductivity, vol. 21, no. 3, pp. 1155-1158, 2011.

[13] J. F. Conroy and R. Watson, "Frequency response capability of full converter wind turbine generators in comparison to conventional generation," IEEE Transactions on Power Systems, vol. 23, no. 2, pp. 649-656, 2008.

[14] J. A. Baroudi, V. Dinavahi, and A. M. Knight, "A review of power converter topologies for wind generators," Renewable Energy, vol. 32, no. 14, pp. 2369-2385, 2007.

[15] P. Kundur, Power System Stability and Control, McGraw-Hill, New York, NY, USA, 1994.

[16] S. Kahphooi, M. Zhihong, and H. R. Wu, "Nonlinear adaptive RBF neural filter with Lyapunov adaptation algorithm and its application to nonlinear channel equalization," in Proceedings of the 5th International Symposium on Signal Processing and Its Applications (ISSPA '99), vol. 1, pp. 151-154, Brisbane, Australia, 1999.

[17] F. D. Bianchi, H. De Battista, and R. J. Mantz, Wind Turbine Control Systems: Principles, Modelling and Gain Scheduling Design, Springer, Berlin, Germany, 2006.

[18] P. Caselitz, W. Kleinkauf, T. Krüger, J. Petschenka, M. Reichardt, and K. Storzel, "Reduction of fatigue loads on wind energy converters by advanced control methods," in Proceedings of the proceedings of the European Wind Energy Conference (EWEC '97), pp. 555-558, October 1997.

[19] H. Jafarnejadsani, J. Pieper, and J. Ehlers, "Adaptive control of a variable-speed variable-pitch wind turbine using RBF neural network," in Proceedings of the IEEE Electrical Power and Energy Conference (EPEC'12), pp. 216-222, London, UK, October 2012.

[20] Y. Song, X. Li, and W. Cai, "Adaptive and fault-tolerant reactive power compensation in power systems via multilevel STATCOMs," International Journal of Innovative Computing, Information and Control, vol. 9, no. 8, pp. 3403-3413, 2013.

[21] D. Niu and Y. Wei, "A novel social-environmental-economic dispatch model for thermal/wind power generation and application," International Journal of Innovative Computing, Information and Control, vol. 9, no. 7, pp. 3005-3014, 2013.
[22] X. Su, P. Shi, L. Wu, and Y.-D. Song, "A novel control design on discrete-time Takagi-Sugeno fuzzy systems with time-varying delays," IEEE Transactions on Fuzzy Systems, vol. 21, no. 4, pp. 655-671, 2013.

[23] L. Wu, X. Su, and P. Shi, "Output feedback control of Markovian jump repeated scalar nonlinear systems," IEEE Transactions on Automatic Control, vol. 59, no. 1, pp. 199-204, 2014.

[24] L. Wu, X. Su, and P. Shi, "Sliding mode control with bounded $\mathscr{L}_{2}$ gain performance of Markovian jump singular time-delay systems," Automatica, vol. 48, no. 8, pp. 1929-1933, 2012.

[25] L. Wang, S. Zuo, Y. D. Song, and Z. Zhou, "Variable torque control of offshore wind turbine on spar floating platform using advanced RBF neural network," Abstract and Applied Analysis, vol. 2014, Article ID 903493, 7 pages, 2014.

[26] S. Zuo, Y. D. Song, L. Wang, and Q.-W. Song, "Computationally inexpensive approach for pitch control of offshore wind turbine on barge floating platform," The Scientific World Journal, vol. 2013, Article ID 357849, 9 pages, 2013.

[27] Y. Chen, G. Mei, G. Ma, S. Lin, and J. Gao, "Robust adaptive inverse dynamics control for uncertain robot manipulator," International Journal of Innovative Computing, Information and Control, vol. 10, no. 2, pp. 575-587, 2014.

[28] S. Bououden, M. Chadli, F. Allouani, and S. Filali, "A new approach for fuzzy predictive adaptive controller design using particle swarm optimization algorithm," International Journal of Innovative Computing, Information and Control, vol. 9, no. 9, pp. 3741-3758, 2013. 


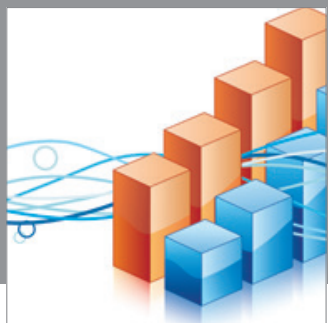

Advances in

Operations Research

mansans

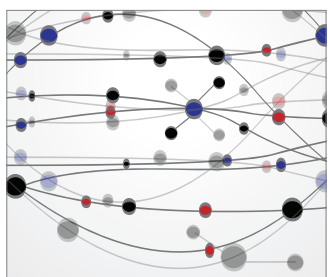

The Scientific World Journal
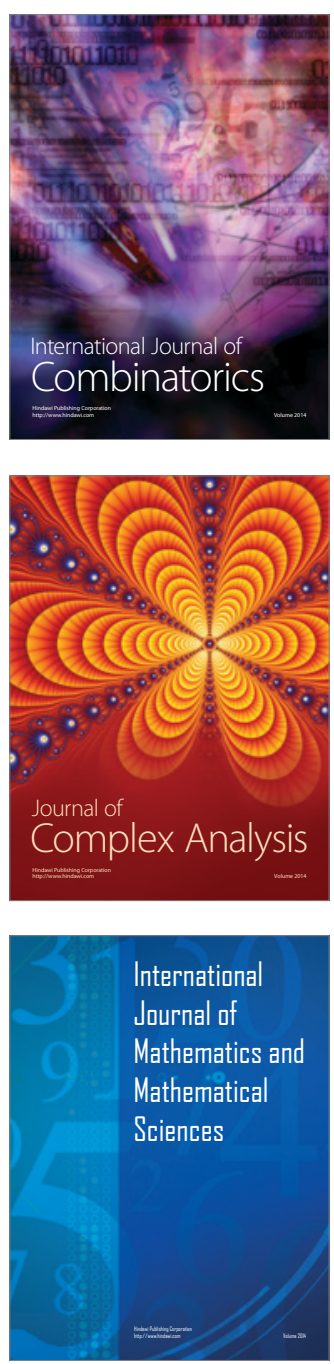
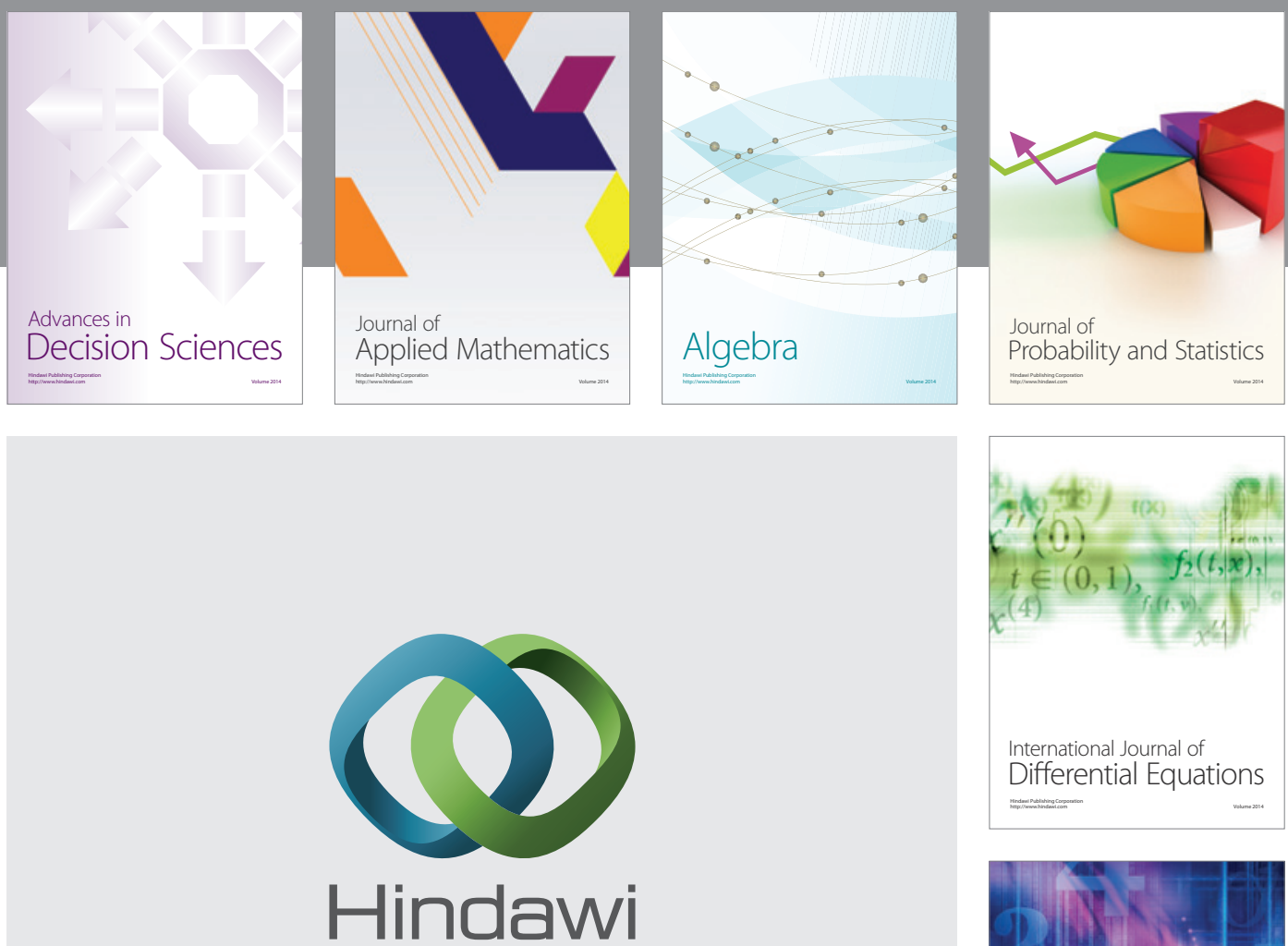

Submit your manuscripts at http://www.hindawi.com
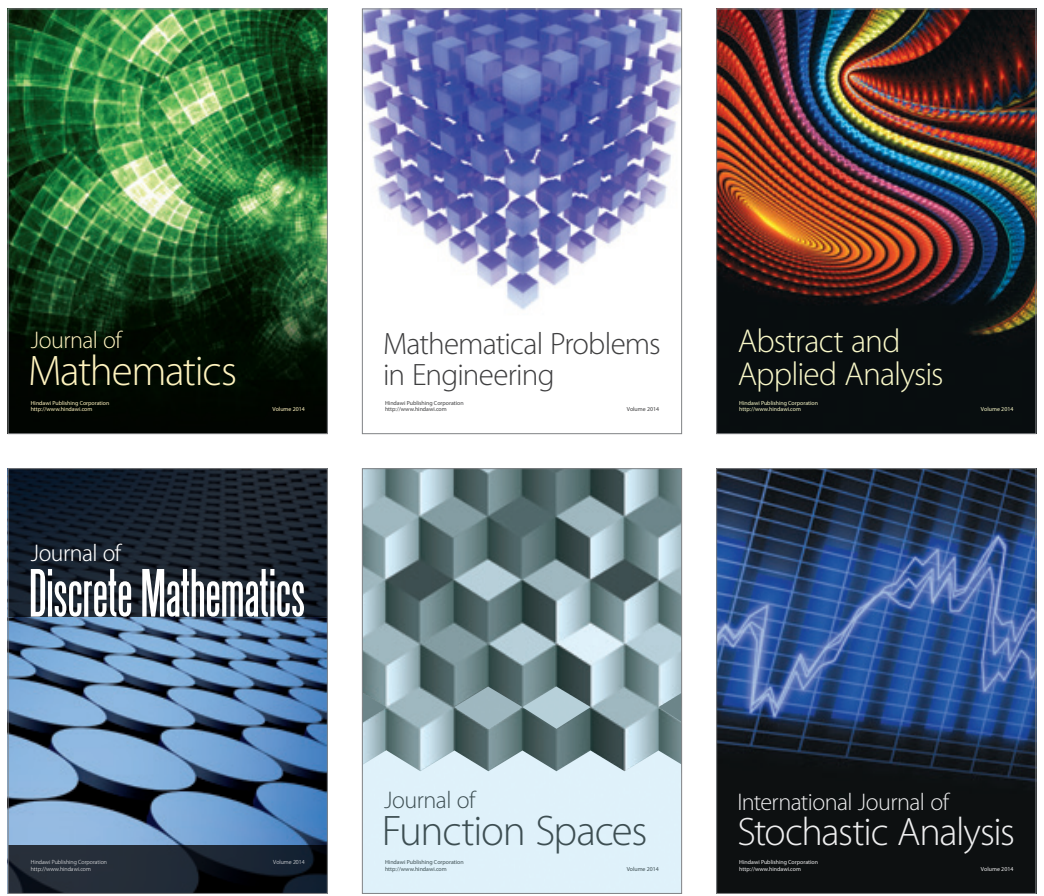

Journal of

Function Spaces

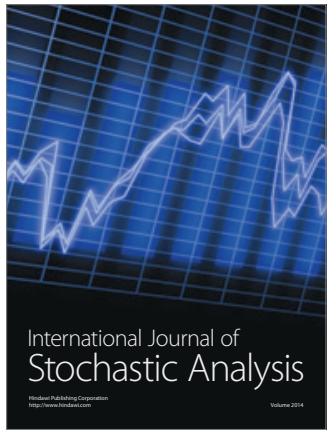

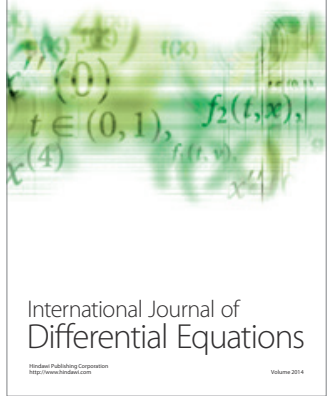
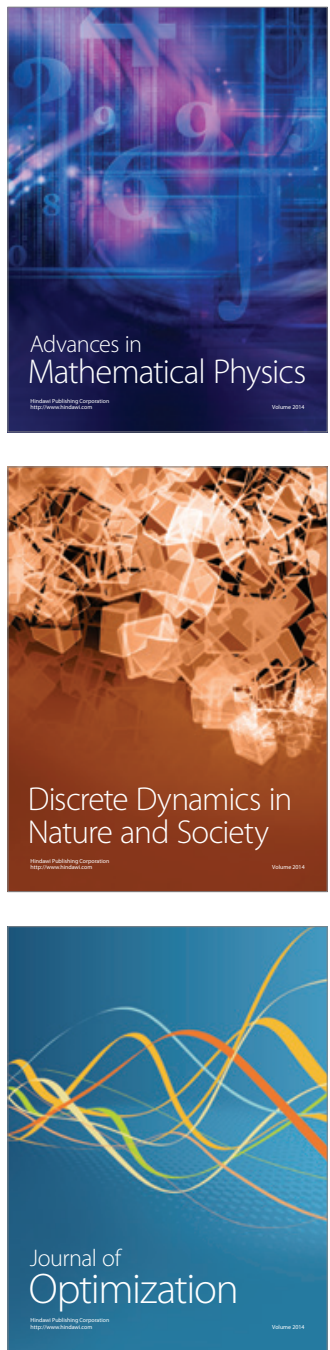